\title{
Orthodontic Treatment Knowledge among General Dentists and Non-orthodontic Specialists
}

\author{
Dr Asal Acharya,' Dr Praveen Mishra,2 Dr Rabindra Man Shrestha, ${ }^{2}$ Dr Pooja Shah4 \\ 1.4PG Resident, ${ }^{2,3}$ Professor, Department of Orthodontics \\ Kantipur Dental College, Kathmandu, Nepal
}

Correspondence: Dr Asal Acharya; Email: asal118@gmail.com

\section{ABSTRACT}

Introduction: General dentists and specialists other than orthodontist may encounter patient requiring orthodontic treatment. For proper counseling and referral, it is important that general dentists and non-orthodontic specialists have adequate level of orthodontic knowledge.

Objective: To assess the knowledge of orthodontic treatment among general dentists and non-orthodontic specialists and to compare the knowledge between the two groups.

Materials \& Method: A descriptive cross sectional study using questionnaire was performed among 185 actively practicing general dentists and non-orthodontic specialists of Nepal. The questionnaire comprised of three parts. The first part included demographic details, second part contained 5 multiple choice questions regarding orthodontic counseling and third part integrated 18 questions for evaluating knowledge of orthodontic treatment. Each correct answer was given score 1 and every incorrect answer was scored zero in the third part of the questionnaire.

Result: Among total participants, $60.5 \%$ think first orthodontic evaluation of a child should be carried out within 7 to 8 years of age and $44.3 \%$ think orthodontic treatment can even be started after 40 years of age. Around $66 \%$ of the participants think that orthodontic treatment cannot be performed in periodontally compromised cases. No significant difference was found between the mean scores of knowledge among general dentists and non-orthodontic specialists $(p=0.891)$, or among dentists with different years of experience $(p=0.644)$.

Conclusion: There is a need for more education of orthodontic treatment concepts to the dentists who do not belong to orthodontic field for proper counseling and referral.

Keywords: General dentist, malocclusion, non-orthodontic specialist, orthodontist

\section{INTRODUCTION}

Malocclusion is the second most common dental disease after dental caries in children and young adults. It is the most commonly recognized etiology for the advancement of dental caries, temporomandibular dysfunctions, gingival and periodontal pathologies.' Furthermore, malocclusion can result social embarrassment, rejection and inevitable psychological disorders. ${ }^{2,3}$ Orthodontic care performed after the professional evaluation or patient self-awareness results in beneficial effects, including aesthetic enhancement, functional improvement, and psychosocial well-being. ${ }^{3-5}$

General public should be aware about cause, consequences and the benefits of orthodontic treatment. ${ }^{4}$ This can be accomplished by a multidisciplinary approach in which general dental practitioners and other non-orthodontic specialists can play the role of orthodontic health educators. Possible differences in educational training, perception of orthodontic treatment need may differ by dentist group or specialty affiliation. ${ }^{6,7}$ Sometimes, patient might present with complain that they cannot correlate with the underlying malocclusion. In such case, it is essential for a dentist to identify and diagnose the orthodontic cause and advice for a referral. ${ }^{8}$

Therefore, there is a need to identify the knowledge level of general dental practitioners and nonorthodontist specialists with respect to the orthodontic treatment. The objective of the study was to assess the knowledge of orthodontic treatment among general dentists and non-orthodontic specialists and to compare the knowledge of orthodontic treatment between the two groups. 


\section{MATERIALS AND METHOD}

Present study is a descriptive cross sectional study carried out among general dentists and non-orthodontic specialist working in different institutions and dental clinics of Nepal. The ethical approval was taken from Institutional Review Committee of Kantipur Dental College. The study was carried out from January 2018 to March 2018. A written consent was taken from every participant of the study.

This is a questionnaire based study. The questionnaire was developed with reference to different studies.3.5,6,9 The questionnaire was first validated by pre-test. The questionnaire comprised of three parts with a total of twenty three questions. First part included demographic details, second part contained 5 multiple choice questions regarding orthodontic counseling and third part integrated 18 questions for evaluating knowledge on orthodontic treatment. The third part had yes or no as answers, each correct answer was scored 1 and every incorrect answer was scored zero. The individual scores were summed up to obtain the total score.

Dental surgeons and non-orthodontic specialists who are actively involved in providing oral health care in hospitals and private clinics were included in the study. Dentists who are not presently practicing dentistry were excluded from the study.

Questionnaire were distributed to 225 participants (approximately $25 \%$ of active dentist in Nepal)..$^{10}$ The questionnaires was distributed proportionately among general dentists and non-orthodontic specialists into 2:1 ratio. Excluding non-respondents, total filled questionnaires collected was 185. The study group was then divided into two groups. Group I comprised of general dentists and Group II included non-orthodontic specialists with a master degree in any subject of dentistry other than orthodontics.

Statistical analysis was done using IBM SPSS software version 21. Mann-Whitney $U$ test and Kruskal-Wallis test were performed as the data were not normally distributed. Significance level was set at $p \leq 0.05$.

\section{RESULT}

The study population included 185 total participants out of which 124 were general dentists and 61 were nonorthodontic specialists. Among them 92 were male and 93 were female. $31 \%$ of the participants had experience of 2 years or less, $40 \%$ had experience of 2-6 years and $29 \%$ had greater than 6 years of experience. Frequency distribution of participants according to qualification is given in Figure 1.

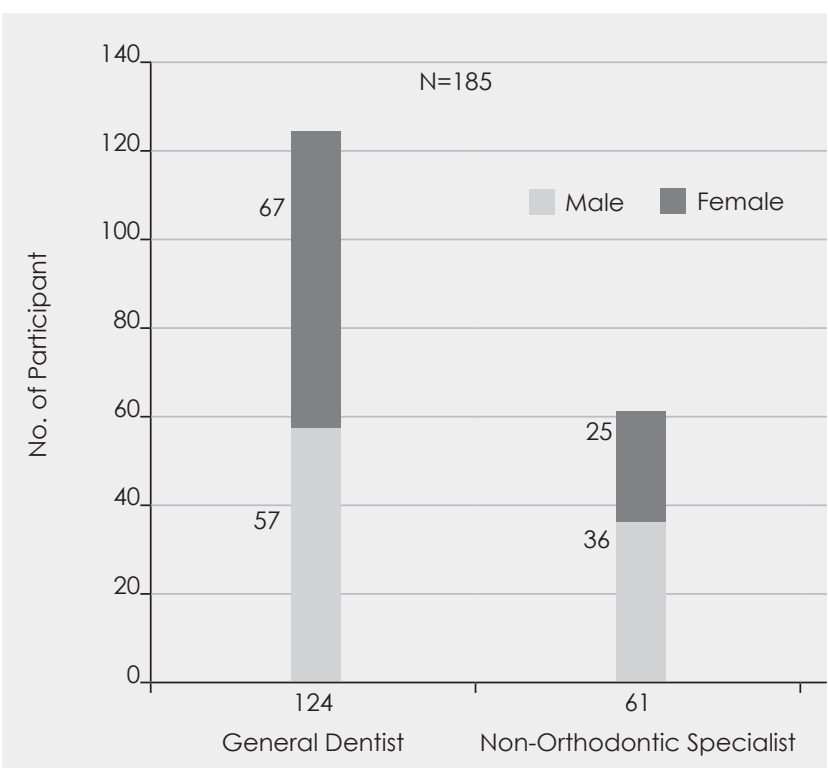

While evaluating the knowledge on orthodontic treatment for counseling of the patients, $60.5 \%$ of the participants think first orthodontic evaluation of a child should be carried out within 7 to 8 years of age. $44.3 \%$ of the participants think that orthodontic treatment can be started after 40 years of age. $88.1 \%$ of the participants think that average duration of the orthodontic treatment is $2-3$ years. $47 \%$ think that retainer should be worn for 6-12 months after orthodontic treatment. $83.2 \%$ participants think that only tipping movement can be achieved by the removable appliance (Table 1).

Table 1: Responses on questions regarding orthodontic counseling

\begin{tabular}{|c|c|c|}
\hline Classification of participants & Response & Frequency \\
\hline \multirow{3}{*}{$\begin{array}{l}\text { When should first orthodontic } \\
\text { evaluation of a child be } \\
\text { performed? }\end{array}$} & 7-8 years* & $60.5 \%$ \\
\hline & 10-12 years & $36.2 \%$ \\
\hline & $15-16$ years & $3.3 \%$ \\
\hline \multirow{3}{*}{$\begin{array}{l}\text { What is maximum age that } \\
\text { orthodontic treatment can be } \\
\text { carried out? }\end{array}$} & $25-30$ years & $22.7 \%$ \\
\hline & $35-40$ years & $33.0 \%$ \\
\hline & $>40$ years* & $44.3 \%$ \\
\hline \multirow{3}{*}{$\begin{array}{l}\text { What is average orthodontic } \\
\text { treatment duration time? }\end{array}$} & 2-3 years* & $88.1 \%$ \\
\hline & 3-4 years & $10.3 \%$ \\
\hline & $>4$ years & $1.6 \%$ \\
\hline \multirow{3}{*}{$\begin{array}{l}\text { How long retainers are to } \\
\text { be worn after orthodontic } \\
\text { treatment? }\end{array}$} & $0-6$ months & $13.5 \%$ \\
\hline & 6-12 months* & $47.0 \%$ \\
\hline & 12-18 months & $39.5 \%$ \\
\hline \multirow{3}{*}{$\begin{array}{l}\text { Cases that can be treated with } \\
\text { removable appliances requires } \\
\text { which type of tooth movement? }\end{array}$} & Tipping* & $83.3 \%$ \\
\hline & Translation & $3.2 \%$ \\
\hline & Both & $13.5 \%$ \\
\hline
\end{tabular}

*most appropriate answer 
Table 2 depicts the knowledge assessment of the participants in relation to the orthodontic treatment. The response to 18 questions in the third section was sought in yes or no dichotomous answers. Each correct answers was given score 1 and incorrect answer was scored as 0 . The individual scores were summed up to obtain the total score, maximum obtainable score being 18 .

Table 2: Knowledge assessment of participants

\begin{tabular}{|c|c|c|c|c|c|c|c|c|c|}
\hline \multirow[b]{2}{*}{ SN } & \multirow{2}{*}{ Question } & \multirow{2}{*}{ Response } & \multicolumn{2}{|c|}{ Qualification } & \multicolumn{2}{|c|}{ Gender } & \multicolumn{3}{|c|}{ Experience } \\
\hline & & & $\begin{array}{l}\text { General } \\
\text { Dentists }\end{array}$ & $\begin{array}{l}\text { Specialists } \\
\text { (non-ortho) }\end{array}$ & Male & Female & $<2 \mathrm{yr}$ & $2-6 \mathrm{yr}$ & $>6 \mathrm{yr}$ \\
\hline \multirow{2}{*}{1} & \multirow{2}{*}{$\begin{array}{l}\text { Can ortho treatment be done in } \\
\text { mixed dentition? }\end{array}$} & Yes & 93 & 47 & 72 & 68 & 38 & 59 & 43 \\
\hline & & No & 31 & 14 & 21 & 24 & 19 & 15 & 11 \\
\hline \multirow{2}{*}{2} & \multirow{2}{*}{$\begin{array}{l}\text { Do functional appliances have } \\
\text { advantages? }\end{array}$} & Yes & 111 & 58 & 86 & 83 & 48 & 71 & 50 \\
\hline & & No & 13 & 3 & 7 & 9 & 9 & 3 & 4 \\
\hline \multirow{2}{*}{3} & \multirow{2}{*}{$\begin{array}{l}\text { Does ortho treatment always require } \\
\text { extraction? }\end{array}$} & Yes & 5 & 2 & 5 & 2 & 2 & 2 & 3 \\
\hline & & No & 119 & 59 & 88 & 90 & 55 & 72 & 51 \\
\hline \multirow{2}{*}{4} & \multirow{2}{*}{$\begin{array}{l}\text { Does malocclusion induce TMJ } \\
\text { disorder? }\end{array}$} & Yes & 120 & 58 & 88 & 90 & 56 & 73 & 49 \\
\hline & & No & 4 & 3 & 5 & 2 & 1 & 1 & 5 \\
\hline \multirow{2}{*}{5} & \multirow{2}{*}{$\begin{array}{l}\text { Does malocclusion create perio } \\
\text { complications? }\end{array}$} & Yes & 119 & 58 & 89 & 88 & 57 & 73 & 47 \\
\hline & & No & 5 & 3 & 4 & 4 & 0 & 1 & 7 \\
\hline \multirow{2}{*}{6} & \multirow{2}{*}{$\begin{array}{l}\text { Can miniscrews be used for } \\
\text { anchorage? }\end{array}$} & Yes & 90 & 50 & 75 & 65 & 41 & 57 & 42 \\
\hline & & No & 34 & 11 & 18 & 27 & 16 & 17 & 12 \\
\hline \multirow{2}{*}{7} & \multirow{2}{*}{$\begin{array}{l}\text { Is retainer necessary after every } \\
\text { ortho treatment? }\end{array}$} & Yes & 91 & 47 & 61 & 77 & 49 & 49 & 40 \\
\hline & & No & 33 & 14 & 32 & 15 & 8 & 25 & 14 \\
\hline \multirow{2}{*}{8} & \multirow{2}{*}{$\begin{array}{l}\text { Do differences exist in adult and } \\
\text { adolescent orthodontics? }\end{array}$} & Yes & 109 & 58 & 87 & 80 & 49 & 70 & 48 \\
\hline & & No & 15 & 3 & 6 & 12 & 8 & 4 & 6 \\
\hline \multirow{2}{*}{9} & \multirow{2}{*}{$\begin{array}{l}\text { Is there different treatment timings for } \\
\text { boys and girls? }\end{array}$} & Yes & 99 & 41 & 67 & 73 & 46 & 59 & 35 \\
\hline & & No & 25 & 20 & 26 & 19 & 11 & 15 & 19 \\
\hline \multirow{2}{*}{10} & Can timely intervention prevent & Yes & 108 & 54 & 78 & 84 & 52 & 66 & 44 \\
\hline & orthognathic surgery? & No & 16 & 7 & 15 & 8 & 5 & 8 & 10 \\
\hline 11 & Should every ortho treatment be & Yes & 21 & 11 & 15 & 17 & 8 & 13 & 11 \\
\hline 11 & done by fixed appliances? & No & 103 & 50 & 78 & 75 & 49 & 61 & 43 \\
\hline 12 & Can ortho treatment be done in & Yes & 40 & 22 & 34 & 28 & 22 & 19 & 21 \\
\hline 12 & perio-compromised cases? & No & 84 & 39 & 59 & 64 & 35 & 55 & 33 \\
\hline & Can certain TMJ disorder be cured & Yes & 116 & 57 & 88 & 85 & 54 & 72 & 47 \\
\hline 13 & by ortho treatment? & No & 8 & 4 & 5 & 7 & 3 & 2 & 7 \\
\hline 14 & Can every malocclusion be treated & Yes & 22 & 11 & 14 & 73 & 11 & 9 & 13 \\
\hline 14 & with lingual braces? & No & 102 & 50 & 79 & 19 & 46 & 65 & 41 \\
\hline 15 & Can every malocclusion be treated & Yes & 27 & 19 & 22 & 68 & 14 & 18 & 14 \\
\hline 10 & with ceramic braces? & No & 97 & 42 & 71 & 24 & 43 & 56 & 40 \\
\hline (3) & Can every malocclusion be treated & Yes & 57 & 24 & 41 & 40 & 26 & 36 & 19 \\
\hline 10 & with clear aligners? & No & 67 & 37 & 52 & 52 & 31 & 38 & 35 \\
\hline 17 & Can ortho treatment be done in & Yes & 115 & 55 & 85 & 85 & 52 & 70 & 48 \\
\hline 17 & missing molar cases? & No & 9 & 6 & 8 & 7 & 5 & 4 & 6 \\
\hline 10 & Can ortho treatment be done in & Yes & 63 & 36 & 54 & 45 & 33 & 30 & 36 \\
\hline 18 & special health care needs? & No & 61 & 25 & 39 & 47 & 24 & 44 & 18 \\
\hline
\end{tabular}


Table 3: Comparison of knowledge and distribution according to group

\begin{tabular}{|c|c|c|c|c|c|c|c|}
\hline \multirow{2}{*}{\multicolumn{2}{|c|}{ Classification of participants }} & \multirow{3}{*}{$\begin{array}{c}\mathbf{N} \\
124\end{array}$} & \multirow{3}{*}{$\begin{array}{c}\text { Knowledge } \\
\text { score } \\
\text { (mean } \pm \text { SD) } \\
13.74 \pm 2.32\end{array}$} & \multirow{4}{*}{$\begin{array}{c}\text { p-Value } \\
0.891 \\
\text { NS }\end{array}$} & \multicolumn{3}{|c|}{ Grade } \\
\hline & & & & & \multirow{2}{*}{$\begin{array}{c}\text { Poor } \\
2\end{array}$} & \multirow{2}{*}{$\begin{array}{c}\text { Fair } \\
30\end{array}$} & \multirow{2}{*}{$\begin{array}{c}\text { Good } \\
92\end{array}$} \\
\hline \multirow{2}{*}{ Qualification } & General dentists & & & & & & \\
\hline & Specialists (non-ortho) & 61 & $13.87 \pm 1.75$ & & 0 & 13 & 48 \\
\hline \multirow{2}{*}{ Gender } & Male & 93 & $14.01 \pm 2.13$ & \multirow{2}{*}{$\begin{array}{c}0.123 \\
\text { NS }\end{array}$} & 1 & 18 & 74 \\
\hline & Female & 92 & $13.55 \pm 2.14$ & & 1 & 25 & 66 \\
\hline \multirow{3}{*}{ Experience } & $<2$ years & 57 & $13.68 \pm 1.91$ & \multirow{3}{*}{$\begin{array}{c}0.644 \\
N S\end{array}$} & 0 & 17 & 40 \\
\hline & $2-6$ years & 74 & $14.00 \pm 1.84$ & & 0 & 16 & 58 \\
\hline & $>6$ years & 54 & $13.59 \pm 2.69$ & & 2 & 10 & 42 \\
\hline \multicolumn{2}{|r|}{ Total } & 185 & $13.78 \pm 2.14$ & - & $2(1.08 \%)$ & $43(23.24 \%)$ & $140(75.68 \%)$ \\
\hline
\end{tabular}

NS, Not significant

Mean score of knowledge among general dentists was 13.74 \pm 2.32 . Mean score of knowledge among non-orthodontic specialist was $13.87 \pm 1.75$. There was no significant difference between the mean score of knowledge among general dentists and non-orthodontic specialists ( $p=0.891$ ) (Table 3 ).

In the present study, the mean score of knowledge was also evaluated by categorizing it in three grades. Mean score 0 to 6 was given poor, mean score 6.1 to 12 was given fair and mean score 12.1 to 18 was good. Distribution in different grades is given in Table 3.

\section{DISCUSSION}

While evaluating the perception of the orthodontic treatment for the counseling of the patients, Table 1 shows that most of the general dentists and the nonorthodontic specialists were aware of the basic concept of the orthodontic treatment. However, around $40 \%$ of the participants aren't aware that first orthodontic evaluation should be done around 7-8 years and around 55\% think that orthodontic treatment cannot be performed after 40 years. This lack of knowledge is very vital for the patient counseling and referral at the correct age for the optimal outcome of the orthodontic treatment. This shows the need for increased in clinically oriented education of practice and concepts of orthodontic treatment.

There was no significant difference between the mean score of knowledge among general dentists and nonorthodontic specialists ( $p=0.891)$. In a similar study done to assess the knowledge of principle and practice of orthodontic treatment among general dentists and nonorthodontics specialists, the mean score of knowledge was found 8.87 and 10.24 respectively. ${ }^{8}$ In this study, the mean score of knowledge in general dentists and nonorthodontic specialist was 13.74 and 13.87 respectively. The difference in mean knowledge was due to difference in number of questions asked and scoring pattern. Another study done by Niveda and Dinesh in Chennai, India on a similar study sample, the knowledge and awareness prevalent among the study participants was found to be moderately satisfactory. ${ }^{?}$

In contrast to the present study, study done by Kapoor et al. have shown statistically significant knowledge and attitude difference between general dentists and nonorthodontic specialists. ${ }^{8}$ Similarly, Sastri et al. showed that the scores were more for the non-orthodontic specialists and the difference was statistically significant. ${ }^{6}$ In another study done in Saudi Arabia, when the scores of knowledge were compared between general dental practitioner and non-orthodontic specialties, a statistically significant difference was noted.

Table 2 shows that approximately $96 \%$ of the participant think that malocclusion can create periodontal complication and can cause temporomandibular disorders. Around $93.5 \%$ think that certain temporomandibular joint disorders can be cured by orthodontic treatment, whereas $66.48 \%$ of the participants think that orthodontic treatment cannot be performed in periodontally compromised cases. Around $53.51 \%$ of the participants think that orthodontic treatment can be done in special health care need patient. Study done by Alshammery et al. also showed that dentist and specialists other than orthodontists are moderately aware about orthodontic treatment in medically compromised patient. ${ }^{11}$ 
The present study highlights the need of better education of treatment concepts in orthodontics to the dentists who do not belong to this specialized field.

\section{CONCLUSION}

Around $25 \%$ of the participant had poor or fair orthodontic knowledge. The other $75 \%$ though classified as having good orthodontic knowledge had mean score towards lower limit of the range for good category. Hence, the present result suggests that the existing knowledge and approach of general dentists as well as non-orthodontic specialists towards orthodontic treatment should be improved. Syllabus of under graduation orthodontics should include more emphasis on therapeutic concepts to fulfill this knowledge gap. Continuing Dental Education (CDE) programs can be helpful for general dentists and non-orthodontic specialists to upgrade their knowledge of orthodontic treatment which in turn will result in proper counseling and referral.

\section{ACKNOWLEDGEMENT}

I would like to express my gratitude towards Dr Sujita Shrestha, Dr Sunita Khanal and Dr Rosina Bhattarai, faculties, Department of Community Dentistry, Kantipur Dental College for their valuable advice, teachings and support regarding statistical analysis.

I would also like to express my gratitude towards teachers Dr Jyoti Dhakal, Dr Ujjwal Pyakurel, Dr Alka Gupta, faculties, Department of Orthodontics, Dr Radha Baral and Dr Bidhata Ojha, faculties, Department of Oral Pathology, Kantipur Dental College for guiding me in manuscript writing and my colleague Dr Diwash Adhikari for helping me in data collection.

\section{REFERENCES}

1. Alnusayri MO, Kuraymalenazi KK, Patil SR, Aileni KR, Rao KA. Knowledge and attitude regarding principles and practices of orthodontic treatment among general dental practitioners and non-orthodontic specialists of Saudi Arabia : A preliminary study. J Res Med Dent Sci. 2017:5(3):59-62.

2. Essamet M, Darout IA. Knowledge and attitude toward orthodontic treatment among treated subjects compared with untreated subjects and correlation with atient - orthodontist communication. World J Dent. 2017:8(3):218-23.

3. Moshkelgosha $\mathrm{V}$, Kazemi M, Pakshir H, Safari R. Parental knowledge and attitude towards early orthodontic treatment for their primary school children. Iran J Orthod. 2016;12(2):e7377.

4. Soni UN, Baheti MJ, Dash S, Toshniwal NG, Baldawa RS. Knowledge and awareness of malocclusion among rural population in India. Asian Pacific J Heal Sci. 2014;1 (4):329-34.

5. Ravichandran P. Parents knowledge and attitude of orthodontic treatment towards their school going children in Chennai - A Questionnaire Survey. J Clin Dent Sci. 2017;2(1):5-11.

6. Sastri MR, Tanpure VR, Palagi FB, Shinde SK, Ladhe K, Polepalle T. Study of the knowledge and attitude about principles and practices of orthodontic treatment among general dental practitioners and non-orthodontic specialties. J Int Oral Heal. 2015;7(3):44-8.

7. Berk NW, Bush HD, Cavalier J, Kapur R, Weyant RJ, Bush HD, et al. Perception of orthodontic treatment need: Opinion comparisons of orthodontists, pediatric dentists, and general practitioners. J Orthod. 2002;29(2016):287-91.

8. Kapoor D, Bhatia S, Garg D. Assessment of the attitude and knowledge of the principles and practices of orthodontic treatment among the non-orthodontic specialists and general practitioner dentists. J Nepal Med Assoc. 2018;56(212):766-9.

9. Niveda S, Dinesh S. A survey of the knowledge, attitude and awareness of principles and practices in orthodontics among general dentists and non-orthodontic specialists. J Dent Med Sci. 2014;13(1):44-6.

10. Shrestha RM, Shrestha S, Kunwar N. Dentists in Nepal : A situation analysis. J Nepal Health Res Counc. 2017;15(2):187-92.

11. Alshammery D, Eid HA, Ajaji NA, Kazim S, Ayed LA. Level of awareness towards orthodontic treatment for medically compromised patients among dental practitioners in Saudi Arabia. J Dent Heal Oral Disord Ther. 2016;5(2):1-5. 